\title{
Unit of Volumetric Electrical Charge Density
}

National Cancer Institute

\section{Source}

National Cancer Institute. Unit of Volumetric Electrical Charge Density. NCI Thesaurus.

Code C68777.

A unit for measurement of electrical charge distribution over volume. 